\title{
ANALISIS RANTAI PASOK CABAI RAWIT DI DESA CIANDUM KECAMATAN CIPATUJAH KABUPATEN TASIKMALAYA
}

\author{
SUPPLY CHAIN ANALYSIS OF CHILLI PEPPER IN CIANDUM VILLAGE, \\ CIPATUJAH DISTRICT, TASIKMALAYA REGENCY
}

\author{
AGIT PURNAMA ${ }^{1} *$, TRISNA INSAN NOOR ${ }^{2}$, MUHAMAD NURDIN YUSUF $^{1}$ \\ ${ }^{1}$ Fakultas Pertanian, Universitas Galuh Ciamis \\ ${ }^{2}$ Fakultas Pertanian Universitas Padjajaran \\ *E-mail : agitpurnama196@gmail.com
}

\begin{abstract}
ABSTRAK
Komoditas hortikultura yang banyak dikembangkan saat ini di Kecamatan Cipatujah yaitu cabai rawit yang mempunyai potensi menjadi komoditas unggulan baru. Namun permasalahan yang dihadapi para petani di Desa Ciandum saat ini adalah fluktuasi harga yang berpengaruh terhadap pendapatan petani. Salah satu penyebabnya diakibatkan oleh manajemen rantai pasokan yang tidak efisien. Penelitian ini bertujaun untuk mengethui; 1) Rantai pasokan terkait dengan aliran produk, aliran informasi serta aliran keuangan pada komoditas cabai rawit dan 2)Tingkat efisiensi rantai pasokan cabai rawit di Desa Ciandum Kecamatan Cipatujah Kabupaten Tasikmalaya. Metode yang digunakan untuk menganalisis rantai pasokan adalah dengan pendekatan Food Supply Chain Network dan analisis deskriptif. Kinerja rantai pasokan cabai rawit diukur dengan efisiensi pemasaran yang menggunakan kriteria marjin pemasaran dan farmer's share. Hasil penelitian menunjukkan bahwa terdapat satu rantai pasokan cabai rawit di Desa Ciandum Kecamatan Cipatujah yang melibatkan petani, pengepul lokal, tengkulak pasar, pengecer, dan konsumen. Aliran produk, aliran keuangan dan aliran informasi berada pada kategori lancar pada setiap rantai pasokan. Tingkat efisiensi rantai pasokan belum efisien. Nilai margin pemasaran untuk setiap satu kilogram cabai rawit adalah sebesar Rp 9.000. Nilai share keuntungan sebesar $89,20 \%$ dan share biaya sebesar $10,80 \%$. Sedangkan untuk bagian harga yang diterima petani (farmer share) sebesar 62,50\%.
\end{abstract}

Kata Kunci: cabai rawit, rantai pasokan

\begin{abstract}
The most developed horticultural commodity in Cipatujah District is chilli pepper which has the potential to become a new superior commodity. However, the problem faced by farmers in Ciandum Village at this time is price fluctuations that affect farmers' income. One of the causes is due to inefficient supply chain management. This research aims to understand; 1) Supply chain related to product flow, information flow and financial flow on the commodity of chilli pepper and 2) The level of efficiency of the supply chain of chilli pepper in Ciandum Village, Cipatujah District, Tasikmalaya Regency. The method used to analyze the supply chain is a food supply chain network (FSCN) approach and descriptive analysis. The performance of the chilli pepper supply chain is measured by marketing efficiency using the criteria of marketing margin and farmer share. The results showed that there was one chilli pepper supply chain in Ciandum Village, Cipatujah District, which involved farmers, local collectors, market middlemen, retailers, and consumers. Product flow, financial flow and information flow are in the current category in each supply chain. The efficiency level of the supply chain is not yet efficient. The marketing margin value for each kilogram of cayenne pepper is IDR 9,000. The profit share value is $89,20 \%$ and the cost share is 10,80\%. Meanwhile, the share of price received by farmers (farmer share) is 62,50\%.
\end{abstract}

Keywords: chilli pepper, supply chain 


\section{PENDAHULUAN}

Cabai merupakan salah satu komoditas strategis yang ditetapkan sebagai bagian dari bahan pokok selain beras, jagung, dan kedelai. Jenis cabai yang paling banyak dikonsumsi oleh masyarakat Indonesia yaitu cabai rawit. Cabai rawit umumnya banyak digunakan dalam skala rumah tangga sebagai bahan tambahan masakan untuk memberi citarasa pedas karena memiliki tingkat kepedasan yang lebih tinggi dibandingkan dengan cabai merah besar. Konsumsi cabai rawit nasional cenderung mengalami kenaikan yang relatif tetap. Berdasarkan data pada tiga tahun terakhir (2016-2019), kenaikan rata-rata konsumsi cabai rawit yaitu sebesar 1,6 persen dengan peningkatan konsumsi cabai rawit perkapita pertahun sebesar 0,05 kg/kapita/tahun.

Sentra produksi cabai rawit Indonesia masih terkonsentrasi di Pulau Jawa, sedangkan konsumen cabai tersebar di seluruh wilayah Indonesia. Oleh karena itu, untuk memenuhi kebutuhan disetiap daerah maka distribusi cabai rawit dari sentra produksi akan berpengaruh pada harga di tingkat konsumen.

Tabel 1. Luas Panen, Produksi dan Produktivitas Cabai Rawit Menurut Provinsi Tahun 2019.

\begin{tabular}{clrrr}
\hline No & \multicolumn{1}{c}{ Provinsi } & Luas Panen (Ha) & Produksi (Ton) & Hasil Per Hektar (Ton) \\
\hline 1 & Jawa Barat & 10.555 & 128.494 & 12,17 \\
2 & Jawa Tengah & 23.892 & 148.750 & 6,22 \\
3 & DI Yogyakarta & 1.540 & 10.040 & 6,52 \\
4 & Jawa Timur & 67.767 & 536.098 & 7,91 \\
5 & Banten & 544 & 5.019 & 9,22 \\
\hline & Jumlah & $\mathbf{1 0 4 . 2 9 8}$ & $\mathbf{8 2 8 . 4 0 1}$ & $\mathbf{7 , 9 4}$ \\
\hline
\end{tabular}

Sumber : Kementerian Pertanian, 2020.

Provinsi Jawa Barat sebagai salah satu daerah produksi cabai rawit mempunyai keunggulan kompetitif dengan tingkat produktivitas yang lebih tinggi dibandingkan dengan provinsi lainnya di Pulau Jawa. Sentra produksi cabai rawit Provinsi Jawa Barat berada di Kabupaten Garut yang merupakan salah satu daerah penghasil produk hortikultura.

Kabupaten Tasikmalaya sebagai
salah satu daerah pengembangan

hortikultura di Provinsi Jawa Barat yang secara geografis masih mempunyai areal lahan pertanian yang cukup luas untuk dimanfaatkan. Komoditas cabai banyak diusahakan sebagai komoditas unggulan di beberapa daerah. Jenis cabai yanng diusakan oleh para petani di Kabupatn Tasikmalaya meliputi cabai merah besar, cabai keriting, dan cabai rawit dengan varietas cabai yang ditanam umumnya jenis cabai hybrid. 
Tabel 2. Luas Panen dan Produksi Aneka Jenis Cabai di Beberapa Wilayah di Kabupaten Tasikmalaya Tahun 2019.

\begin{tabular}{llrrr}
\hline No & Kecamatan & \multicolumn{1}{c}{ Luas Panen (ha) } & Produksi (ku) & Produktivitas (ku/ha) \\
\hline 1 & Cipatujah & $\mathbf{5 7}$ & $\mathbf{5 . 3 4 6}$ & $\mathbf{9 3 , 7 9}$ \\
2 & Karangnunggal & 34 & 2.517 & 74,03 \\
3 & Cikalong & 10 & 633 & 63,30 \\
4 & Cibalong & 14 & 998 & 71,29 \\
5 & Bantarkalong & 26 & 2.207 & 84,88 \\
6 & Bojongasih & 19 & 1.890 & 99,47 \\
7 & Culamega & 2 & 125 & 62,50 \\
\hline
\end{tabular}

Sumber : Kabupaten Tasikmalaya Dalam Angka, 2020.

Kecamatan Cipatujah dengan komoditas hortikultura yang banyak dikembangkan saat ini adalah jenis cabai rawit hibrida. Cabai rawit tersebut dapat menjadi komoditas potensial sebagai produk unggulan daerah jika didukung oleh kebijakan pembangunan pertanian yang berkelanjutan.

Desa Ciandum merupakan daerah sentra produksi cabai rawit di Kecamatan Cipatujah. Namun permasalahan yang dihadapi para petani di Desa Ciandum saat ini adalah fluktuasi harga yang berpengaruh terhadap pendapatan petani. Salah satu penyebabnya diakibatkan oleh manajemen rantai pasokan yang tidak efisien. Efisiennya manajemen rantai pasokan dapat tercapai jika pengelolaan dan pengawasan hubungan saluran distribusi dilakukan secara kooperatif oleh semua pihak yang terlibat. Menurut Wijaya dan Sutapa (2013) panjangnya rantai pasok juga dapat mengakibatkan tingginya kerusakan sehingga harga cabai menjadi tinggi.
Pola rantai pasokan atau supply chain merupakan kegiatan yang dilakukan petani dan lembaga-lembaga pemasaran lainnya dalam penyaluran barang, pengolahan barang maupun pengaturanpengaturan lainnya baik itu pengaturan harga dan komunikasi yang didalamnya juga terdapat aliran produk, aliran informasi dan aliran finansial agar keuntungan dapat diraih oleh setiap mata rantai. Dampak dari kegiatan dalam rantai pasokan tersebut adalah adanya penambahan nilai pada produk cabai rawit yang diterima oleh kosumen.

Penelitian ini bertujuan untuk mengetahui rantai pasokan terkait dengan aliran produk, aliran informasi serta aliran keuangan pada komoditas cabai rawit dan tingkat efisiensi rantai pasokan cabai rawit di Desa Ciandum Kecamatan Cipatujah Kabupaten Tasikmalaya.

\section{METODE PENELITIAN}

Penelitian ini merupakan penelitian kuantitatif dengan menggunakan metode 
survei. Pengambilan data primer dilakukan dengan cara wawancara langsung, sedangkan sekunder didapat diperoleh melalui media perantara atau secara tidak langsung yang berupa buku, catatan, bukti yang telah ada, dokumen riset atau arsip yang dipublikasikan maupun tidak dipublikasikan. Analisis data yang digunakan untuk mengetahui rantai pasok cabai rawit dilakukan dengan pendekatan FSCN (Food Supply Chain Network) pemetaan pelaku, pemetaan alur produk, pemetaan alur informasi, dan pemetaan alur keuangan yang disajikan secara deskriptif menurut Vorst (2006).

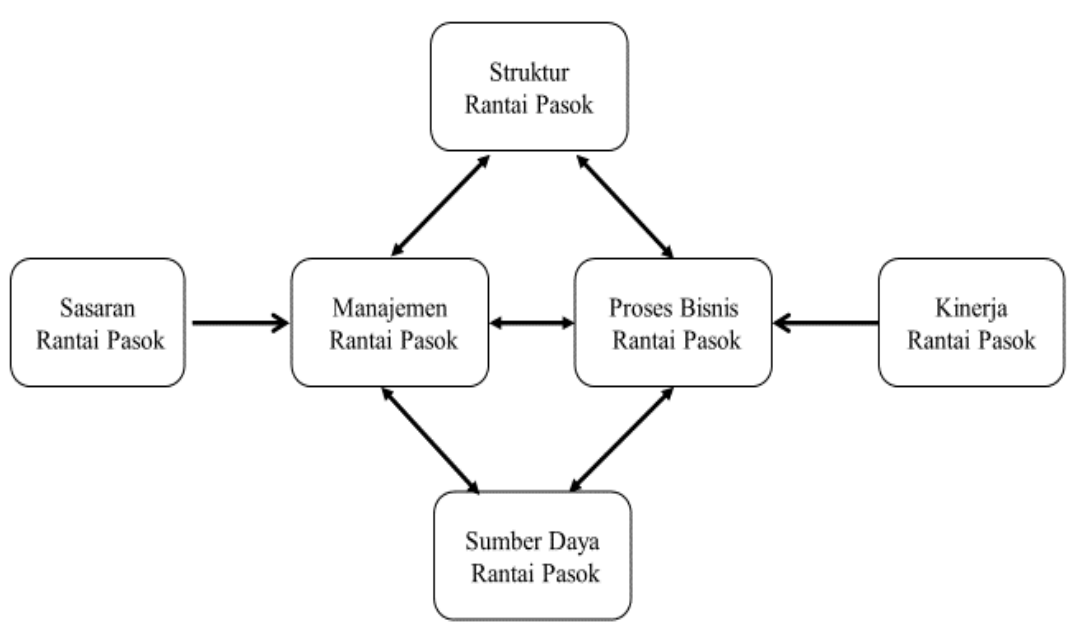

Gambar 1. Kerangka Analisis Deskriptif Rantai Pasok

Sedangkan untuk efisiensi rantai pasokan dianalisis dengan pendekatan efisiensi pemasaran menggunakan marjin pemasaran dan farmer share. Marjin pemasaran merupakan perbedaan harga jual diantara lembaga-lembaga pemasaran. Secara matematis marjin pemasaran dapat ditulis sebagai berikut (Fatimah, 2011 dalam Fadhlullah dkk, 2018):

Keterangan:

$$
\mathrm{MP}=P r-P f
$$

$\mathrm{MP}=$ Marjin pemasaran

Pr $\quad=$ Harga di tingkat konsumen

Pf = Harga di tingkat produsen
Farmer share

merupakan perbandingan antara harga yang diterima petani dengan harga yang dibayarkan konsumen. Secara matematis farmer share dapat ditulis sebagai berikut:

$$
F s=\frac{P f}{P k} \times 100 \%
$$

Keterangan:

Fs : Persentase harga yang diterima petani (\%)

Pf : Harga ditingkat petani $(\mathrm{Rp} / \mathrm{kg})$

$\mathrm{Pk}$ : Harga ditingkat konsumen $(\mathrm{Rp} / \mathrm{kg})$ 
HASIL DAN PEMBAHASAN

Struktur Rantai Pasokan

Struktur rantai pasokan cabai rawit menjelaskan tentang peranan dari masingmasing anggota dari rantai pasokan yang terlibat. Penentuan struktur tersebut dapat dipengaruhi oleh ciri khas dari produk yang dihasilkan, keterlibatan jumlah pelaku rantai, serta jarak ke pasar.

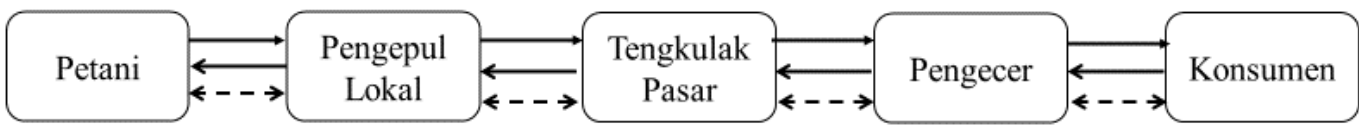

Gambar 2. Struktur Rantai Pasokan Cabai Rawit

Keterangan :

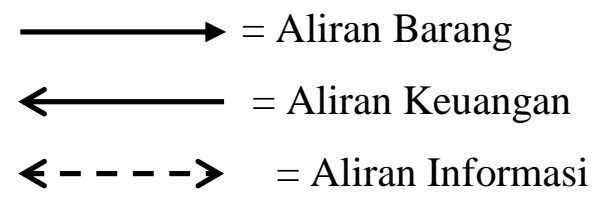

Pada Gambar 3, dapat diketahui bahwa tentang pola aliran rantai pasokan cabai rawit di Desa Ciandum Kecamatan Cipatujah Kabupaten Tasikmalaya terbagi ke dalam 3 jenis, yaitu aliran poduk, aliran infomasi dan aliran keuangan. Terdapat 4 anggota mata rantai yang terlibat dalam mekanisme rantai pasokan cabai rawit di Desa Ciandum Kecamatan Cipatujah Kabupaten Tasikmalaya yaitu, petani, pengepul lokal, tengkulak pasar, dan pengecer.

1. Petani

Petani merupakan pelaku rantai pasokan yang melakukan kegiatan budidaya cabai rawit dari mulai pembibitan, pemeliharaan, sampai proses panen dan pasca panen. Petani cababi rawit merupakan awal dari rantai pasokan cabai rawit di Desa Ciandum. Petani memegang peranan krusial dalam menghasilkan produk dengan kuantitas dan kualitas yang baik.

Cabai rawit yang dihasilkan petani, dijual kepada pedagang pengepul dengan harga sesuai kesepakatan sebelumnya. Pedagang pengepul yang ada hanya berperan sebagai mitra beli hasil produksi petani dengan harga ditetapkan oleh pedagang pengepul. Pola budidaya yang dilakukan belum menerapkan manajemen yang baik, dimana untuk distribusi produksi cabai rawit hanya sesuai dengan jadwal panen dari petani, sehingga ketersediaan cabai rawit tidak selalu ada. Oleh karena itu, petani tidak punya kekuatan untuk menetukan haga atas produk yang dijualnya. Irawan (2007) 
menyatakan bahwa untuk mendapatkan harga yang lebih menguntungkan, petani harus mampu memanfaatkan variasi harga yang terjadi di pasar baik menurut tempat, bentuk produk, waktu maupun kualitas produk dengan mengatur pola penawarannya sesuai dengan kegiatan produksinya dan kegiatan pemasarannya (penyimpanan, sortasi dan grading, outlet pemasaran, dan sebagainya) yang disesuaikan dengan kebutuhan pasar. Petani cabai rawit di daerah penelitian berjumlah 30 orang dengan rata-rata penguasaan lahan seluas 0,21 ha dan produksi rata-rata sebesar 14,01 ton/ha. Penjualan cabai rawit oleh petani hanya dikemas dalam karung plastik, dengan kualitas sesuai keinginan pedagang pengepul.

\section{Pengepul Lokal}

Pengepul lokal merupakan pelaku rantai pasokan setelah petani. Pengepul lokal yaitu pengepul cabai rawit yang berada di wilayah Kecamatan Cipatujah. Pengepul lokal berperan dalam mendistribusikan dan memasarkan cabai rawit petani kepada tengkulak pasar. Petani menjual hasil produksinya tanpa ada batasan jumlah kepada pedagang pengepul. Sebelum dikirim kepada pedagang pasar, cabai rawit disortir kembali jika ada barang yang kualitasnya jelek atau busuk.
Kemudian setelah itu dipacking kembali dengan karung plastik untuk dikirimkan kepada tengkulak pasar.

Pengiriman tersebut berlangsung 3 kali dalam seminggu yaitu pada hari selasa, kamis, dan sabtu pada pagi hari. Kemampuan pengepul lokal untuk menampung cabai rawit mencapai 700 kg/hari. Kegiatan yang dilakukan oleh pedagang pengepul dalam kerangka rantai pasokan cabai rawit secara ringkas antara lain pembelian cabai rawit dari petani, sortasi, distribusi, dan penjualan kepada tengkulak pasar. Disini terjadi resiko penyusutan produk aikbat dari pembusukan, atau produk yang sudah tidak layak jual.

3. Tengkulak Pasar

Pelaku rantai selanjutnya yaitu tengkulak pasar, dengan mempunyai peran untuk mendistribusikan dan memasarkan cabai rawit hasil petani. Tengkulak pasar yang terlibat merupakan tengkulak yang berada di Pasar Cikurubuk. Disini cabai rawit di sortir kembali untuk menentukan kualitas produk yang diinginkan konsumen, yang kemudian dikemas dan dikirimkan kepada para pedagang pengecer Pasar Cikurubuk. Kapasitas penerimaan cabai rawit bisa mencapai $1.500 \mathrm{~kg} / \mathrm{hari}$. Ketentuan harga jual kepada pengecer dilakukan dengan memperhitungkan total 
biaya, keuntungan, penyusutan barang akibat kerusakan dalam distribusi, dan harga beli sebelumnya.

\section{Pengecer}

Pelaku rantai setelah tengkulak pasar yaitu pengecer. Pengecer mempunyai peran untuk mendistribusikan dan memasarkan cabai rawit hasil petani kepada konsumen. Penngecer yang dimaksud adalah pedagang yang berada di Pasar Cikurubuk. Cabai rawit yang didistribusikan oleh tengkulak pasar dijual langsung kepada konsumen dengan harga jual yang sudah ditentukan oleh pengecer, dengan memperhitungkan harga beli, keuntungan, dan resiko penyusutan barang yang diterima pedagang pengecer.

\section{Pola Ditribusi}

Pola distribusi rantai pasokan cabai rawit menjabarkan tiga komponen utama, yakni aliran produk, aliran uang, dan aliran informasi. Penyampaian tiga komponen tersebut sangat penting untuk diketahui agar dapat dianalisis mengenai kelancaran aliran distribusi dalam rantai pasokan.

\section{Aliran Barang}

Produk yang didistribusikan dalam rantai pasokan adalah cabai rawit dengan kualitas baik. Proses distribusinya diawali dari kegiatan pemanenan oleh petani yang kemudian dikemas untuk dikirim ke pengepul lokal. Pengiriman cabai rawit dari petani ke pengepul dilakukan oleh masing-masing petani pada sore hari. Ratarata pasokan dari petani kepada pengepul lokal sebanyak $150 \mathrm{~kg} /$ hari. Sesampainya di pengepul lokal, cabai rawit tersebut ditimbang beratnya dan dilakukan pencatatan untuk dilakukan pembayaran.

Sebelum dikirimkan kepada tengkulak pasar, pengepul lokal melakukan sortasi cabai rawit. Setelah itu dilakukan pengemasan dengan menggunakan karung plastik dan siap untuk dilakukan pengiriman. Pengiriman cabai rawit kepada tengkulak pasar dilakukan pada pagi hari dengan menggunakan kendaraan milik sendiri. Rata-rata pengiriman yang dilakukan oleh pengepul lokal sebanyak $500 \mathrm{~kg}$ per satu kali pengiriman. Pengiriman cabai rawit dilakukan tiga kali dalam satu minggu yang dilakukan pada hari selasa, kamis dan sabtu

Setibanya di tengkulak pasar, cabai rawit ditimbang, disortasi, kemudian langsung didistribusikan ke para pengecer yang ada di Pasar Cikurubuk untuk dijual kepada konsumen. Rata-rata pasokan cabai rawit kepada pengecer sebanyak $30 \mathrm{~kg} / \mathrm{hari}$. Aliran cabai rawit pada rantai pasokan dapat dikategorikan lancar 


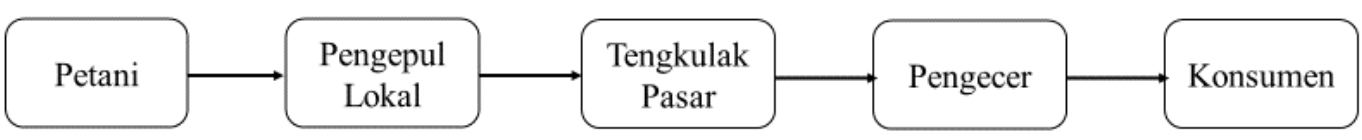

Keterangan : $\longrightarrow$ Aliran Barang Lancar

\section{Gambar 3. Aliran Barang}

\section{Aliran Keuangan}

Pembayaran cabai rawit pengepul lokal kepada petani dilakukan secara tunai pada saat pengiriman dilakukan, sehingga petani dapat melakukan kegiatan budidaya musim tanam berikutnya. Pembayaran cabai rawit dari tengkulak pasar ke pengepul lokal dilakukan secara tunai. Sistem pembayaran yang dilakukan oleh pengecer ke tengkulak pasar dengan sistem bayar tunda satu hari. Aliran uang yang terjadi dalam rantai pasokan dimulai dari pengecer sampai petani dapat dikategorikan lancar

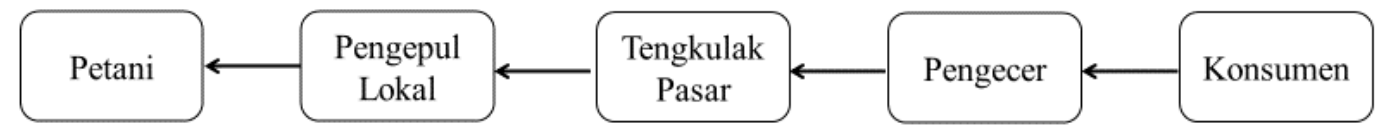

Keterangan :

Aliran Keuangan Lancar

\section{Gambar 4. Aliran Keuangan}

\section{Aliran Informasi}

Aliran distribusi informasi merupakan komponen yang sangat penting untuk diperhatikan guna pencapaian tujuan dari rantai pasokan. Distribusi informasi yang baik di antara pelaku rantai pasokan dapat menciptakan hubungan yang baik dan transparan sehingga mampu meningkatkan kepercayaan serta komitmen dalam menjalankan hubungan kerjasama. Aliran informasi dalam rantai pasokan cabai rawit terdiri dari informasi pasar yang meliputi siapa pasar sasaran akhir (konsumen), bagaimana perilaku dan preferensi konsumen, serta kualitas produk yang diinginkan konsumen.
Informasi pasar yang diperoleh dari tengkulak pasar dari pengecer yaitu informasi terhadap perubahan permintaan terhadap kualitas produk dan kuantitas produk. Penyampaian informasi pasar ini berlangsung pada saat pengiriman cabai rawit. Informasi pasar sangat penting terutama dari konsumen akhir yang menyangkut standar kualitas dan tampilan produk yang digemari. Bentuk informasi yang diperoleh dari tengkulak pasar kepada pengepul lokal yaitu informasi terhadap perubahan harga dan perubahan kuantitas permintaan. Informasi terhadap perubahan harga sangat penting bagi pengepul lokal untuk menentukan harga 
pembelian cabai rawit kepada petani. informasi pada rantai pasokan cabai rawit Kemudian untuk petani cabai rawit, dapat dikategorikan lancar dengan jenis informasi yang diberikan oleh pengepul informasi bersifat asimetris lokal berupa perubahan harga. Aliran

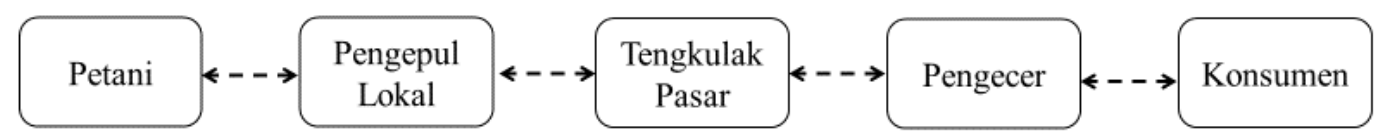

Keterangan : $<-\rightarrow>$ Aliran Informasi Lancar

\section{Gambar 5. Aliran Informasi}

\section{Efisiensi Rantai Pasokan}

Efisiensi rantai pasokan dilakukan dengan menggunakan indikator marjin pemasaran dan farmer share. Penilaian efisiensi rantai pasokan dapat digunakan untuk melihat bagaimana sumberdaya rantai yang telah dialokasikan. Rantai pasokan yang dibahas dalam penelitian ini hanya memiliki satu saluran pemasaran yakni melibatkan petani, pengepul lokal, tengkulak pasar, pengecer dan konsumen.

Tabel 3. Marjin Pemasaran dan Farmer Share dalam Rantai Pasokan Komoditas Cabai Rawit

\begin{tabular}{|c|c|c|c|c|}
\hline \multirow{2}{*}{ No } & \multirow{2}{*}{ Lembaga Pemasaran } & \multirow{2}{*}{ Harga (Rp/Kg) } & \multicolumn{2}{|c|}{ Share Value (\%) } \\
\hline & & & Keuntungan & Biaya \\
\hline \multirow[t]{2}{*}{1} & Petani & & & \\
\hline & Harga Jual & 15.000 & 62,5 & \\
\hline \multirow[t]{8}{*}{2} & Pengepul Lokal & & & \\
\hline & Harga Beli & 15.000 & & \\
\hline & Biaya Transportasi & 250 & & 1,04 \\
\hline & Biaya Tenaga Kerja & 250 & & 1,04 \\
\hline & Biaya Pengemasan & 75 & & 0,31 \\
\hline & Penyusutan & 375 & & 1,56 \\
\hline & Keuntungan & 1.050 & 4,38 & \\
\hline & Harga Jual & 17.000 & & \\
\hline \multirow[t]{7}{*}{3} & Tengkulak Pasar & & & \\
\hline & Harga Beli & 17.000 & & \\
\hline & Biaya Tenaga Kerja & 250 & & 1,04 \\
\hline & Pengemasan & 300 & & 1,25 \\
\hline & Penyusutan & 375 & & 1,56 \\
\hline & Keuntungan & 1.075 & 4,48 & \\
\hline & Harga Jual & 19.000 & & \\
\hline \multirow[t]{8}{*}{4} & Pengecer & & & \\
\hline & Harga Beli & 19.000 & & \\
\hline & Biaya Tenaga Kerja & 167 & & 0,69 \\
\hline & Biaya Pengemasan & 200 & & 0,83 \\
\hline & Biaya Retribusi & 100 & & 0,42 \\
\hline & Penyusutan & 250 & & 1,04 \\
\hline & Keuntungan & 4.283 & 17,8 & \\
\hline & Harga Jual & 24.000 & & \\
\hline \multirow[t]{6}{*}{5} & Konsumen & & & \\
\hline & Harga Beli & 24.000 & & \\
\hline & Total Marjin & 9.000 & & \\
\hline & Total Biaya & 3.642 & & 10,80 \\
\hline & Total Keuntungan & 6.408 & 89,20 & \\
\hline & Farmer share (\%) & & & 62,50 \\
\hline
\end{tabular}

Sumber : Hasil olah data primer, 2020. 
Tabel 11 menunjukkan bahwa lembaga pemasaran cabai rawit yang terkait adalah pengepul lokal, tengkulak pasar, dan pengecer. Pengepul lokal mengeluarkan biaya-biaya seperti biaya transportasi dan pengemasan. Biaya paling tinggi adalah biaya penyusutan, yaitu sebesar Rp 375 per kg. Biaya transportasi yang dikeluarkan oleh pengepul lokal dipengaruhi banyaknya cabai rawit yang dihitung dalam satuan karung dan jarak antara tempat pedagang pasar. Biaya transportasi untuk satu karung yaitu $\mathrm{Rp}$ 10.000 isi kurang lebih $40 \mathrm{~kg}$. Harga beli cabai rawit dari petani produsen sebesar Rp 15.000 per kg dan dijual ke tengkulak pasar sebesar Rp 17.000 per kg. Total biaya ditingkat pengepul lokal sebesar $\mathrm{Rp}$ 950 dan keuntungan sebesar Rp 1.050 per kg. Marjin pemasaran yang diperoleh pengepul lokal sebesar Rp 2.000 per kg.

Selanjutnya tengkulak pasar membeli cabai rawit dari pengepul lokal dengan harga sebesar Rp 17.000 per kg. Tengkulak pasar mengeluarkan biaya pemasaran sebesar $\mathrm{Rp} 925$ per $\mathrm{kg}$, yang terdiri dari biaya tenaga kerja $\mathrm{Rp} 250$ per $\mathrm{kg}$, biaya pengemasan $\mathrm{Rp} 300$ per $\mathrm{kg}$ dan biaya penyusutan Rp 375 per $\mathrm{kg}$. Tengkulak pasar kemudian menjualnya ke pedagang pengecer di Pasar Cikurubuk. Harga jual cabai rawit ke pedagang pengecer adalah sebesar Rp 19.000 per kg. Keuntungan yang diperoleh tengkulak pasar adalah sebesar Rp 1.075 per $\mathrm{kg}$ dan marjin pemasaran sebesar Rp 2.000 per kg.

Pedagang pengecer membeli cabai rawit dari tegkulak pasar dengan harga sebesar Rp 19.000 per kg. Pedagang pengecer mengeluarkan biaya pemasaran sebesar Rp 717 per kg, yang terdiri dari biaya tenaga kerja Rp 167 per kg, biaya restribusi Rp 100 per kg, biaya pengemasan $\mathrm{Rp} 200$ per $\mathrm{kg}$ dan biaya penyusutan Rp 250 per kg. Pengecer kemudian menjualnya ke konsumen dengan harga $\mathrm{Rp} 24.000$ per $\mathrm{kg}$. Keuntungan yang diperoleh pengecer adalah sebesar Rp 4.283 per $\mathrm{kg}$ dan marjin pemasaran sebesar Rp 5.000 per kg.

Nilai total marjin pemasaran cabai rawit sebesar Rp 9.000 per kg, total keuntungan sebesar Rp 6.408 per $\mathrm{kg}$ dan total biaya sebesar Rp 3.642 per $\mathrm{kg}$. Nilai share keuntungan sebesar $89,20 \%$ sedangkan nilai share biaya sebesar $10,80 \%$. Menurut Prayitno, dkk (2013) dalam Kurniawan dkk (2014), jika persentase Pf (Produsen Share $) \leq 70 \%$ maka pemasaran belum dianggap efisien. Bagian harga yang diterima petani (farmer share) sebesar $62,5 \%$ sehigga rantai pasokan cabai rawit di Desa Ciandum Kecamatan Cipatujah 
Kabupaten Tasikmalaya dikategorikan belum efisien

\section{KESIMPULAN DAN SARAN}

\section{Kesimpulan}

Terdapat satu rantai pasokan cabai rawit di Desa Ciandum Kecamatan Cipatujah yang melibatkan petani, pengepul lokal, tengkulak pasar, pengecer, dan konsumen. Aliran produk, aliran keuangan dan aliran informasi berada pada kategori lancar pada setiap rantai pasokan.

Nilai total marjin pemasaran cabai rawit $\mathrm{Rp} 9.000$ per $\mathrm{kg}$ dengan total keuntungan $\mathrm{Rp} 6.408$ per $\mathrm{kg}$ dan total biaya Rp 3.642 per $\mathrm{kg}$. Nilai share keuntungan $89,20 \%$ sedangkan nilai share biaya $10,80 \%$. Bagian harga yang diterima petani (farmer share) 62,5\% sehigga rantai pasokan cabai rawit di Desa Ciandum Kecamatan Cipatujah Kabupaten Tasikmalaya dikategorikan belum efisien karena persentase Pf (Produsen Share) $\leq$ $70 \%$.

\section{Saran}

Kerjasama distribusi barang oleh petani harus lebih ditingkatkan untuk mencari peluang dalam memperluas distribusi cabai rawit. Peningkatan kapasitas produksi dan kualitas cabai rawit harus lebih diutamakan supaya mempunyai posisi tawar yang lebih baik. selain itu, petani harus menekan biaya pemasaran dengan cara membentuk rantai pasokan baru yang lebih tepat (relatif pendek) agar nilai farmer share dapat meningkat.

\section{DAFTAR PUSTAKA}

Badan Pusat Statistik. 2020. Kabupaten Tasikmalaya dalam Angka 2020. Tasikmalaya: Badan Pusat Statistik.

Fadhlullah, A.D., Ekowati, T. dan Mukson. 2018. Analisis Rantai Pasok (Supply Chain) Kedelai di UD Adem Ayem Kecamatan Pulokulon Kabupaten Grobogan. Jurnal Pendidikan Bisnis dan Ekonomi, 4(2) : 1-10.

Irawan, B. 2007. Fluktuasi Harga, Transmisi Harga Dan Marjin Pemasaran Sayuran dan Buah. Analisis Kebijakan Pertanian, 5(4) : 358-373.

Kurniawan, R.D. Suwandari, A. dan Ridjal, J.A. 2014. Analisis Rantai Pasokan (Supply Chain) Komoditas Cabai Merah Besar Di Kabupaten Jember. Berkala ilmiah Pertanian, 114.

van der Vorst. 2006. Performance measurement in agri-food supply chain networks. (p. 13). Netherlands: Logistics and Operations Research Group, Wageningen University.

Wijaya, W.D. dan Sutapa, I.N. Upaya Pengurangan Tingkat Kecacatan Cabai Pasca Panen Pada Jalur Rantai Pasok. Jurnal Titra, 1 (2) : 253-256. 